ledge of the literature but also sophisticated techniques. The greater use of genetic counselling demands a more precise and detailed diagnosis of congenital malformations. Furthermore, the gestational age structure has changed: a majority of neonatal deaths (in contrast to stillbirths) occur in infants of less than 28 weeks' gestation or less than $1 \mathrm{~kg}$ in weight. The smaller the baby the more unlike the adult necropsy are postmortem techniques and problems. Last but not least, owing to the impact of intensive neonatal care there is a changed morphology of neonatal lesions.

Dr Barson and others acknowledge that general pathologists might be stimulated by enthusiastic clinicians to undertake more of this work. I endorse this view: if obstetricians and neonatal paediatricians not only reassured the pathologist that his or her service is wanted and appreciated but also communicated their problems to the pathologist and involved her or him in the search for a solution, this could persuade the general pathologist to give greater priority to perinatal work. General histopathologists, however, will require more training in paediatric and perinatal pathology. In some instances short intensive "refresher" courses might help, but more effective would be the inclusion of a six-month period in a specialised department during the registrar or senior registrar curriculum. To make such a proposal feasible, two conditions must be fulfilled: (1) An adequate number of trainee posts should be created in existing paediatric/perinatal pathology departments. These could be filled on a rotational basis or by special secondment from a general pathology department. (2) The intending genera histopathologist must be reassured that his career prospects are not prejudiced but enhanced by this period of specialised training, even though it prolongs the apprenticeship.

If employing authorities inserted in their advertisements and job descriptions for general histopathologists, in district general hospitals, a sentence like: "Some training/experience in perinatal pathology would be an advantage," this would go a long way to remove any misgivings that trainee pathologists might have. It might also remove the fear of getting trapped in a cul-de-sac by those who are more fully committed to this subspecialty.

H G KoHLER

Department of Pathology,

Glasgow Royal Maternity Hospital,

Potter EL. Pathology of the fetus and the newborn. Chicago: Year Book Publishers, 1952

orison JE. Fetal and neonatal pathology. London:

Butler NR, Bonham

burgh: Livingston, 1963 .

\section{Screening for lung cancer}

SIR, - We read with interest the leading article by Dr Ian W B Grant (24 April, p 1209). In previous reports ${ }^{12}$ we showed a better prognosis for patients who were symptom free (apart from a smoker's cough) and emphasised the serious outlook for those presenting with pain, weight loss of $6 \mathrm{~kg}$ or more, or both.

This screening programme for lung cancer has continued in Dundee, and 95 patients with histologically proved carcinoma have now been followed up for five years or more. Thirty-one $(33 \%)$ of these patients have lived five years or longer, and $14(15 \%)$ for 10 years or more. Two are well 19 years later, and one of these has had a successive middle and left upper lobectomy. The tumour types among the survivors do not differ much from those in the original group (squamous carcinoma $50 \%$, small cell/large cell carcinoma $37 \%$, and adenocarcinoma $13 \%$ ). Of 23 deaths after five years only 14 were due to tumour recurrence.
All except two patients had successful removal of the tumour with $50 \%$ undergoing lobectomy. By contrast the overall survival rate for men in Dundee of the same age is $7 \cdot 2 \%$ at five years. During the years $1978-80$ a four-monthly $x$-ray examination replaced the annual screening survey, but this yielded no significant advantage. Efforts at obtaining satisfactory sputum cytology from these volunteers were unsuccessful because of the poor quality of sputum provided. An annual $x$-ray screening of those at high risk remains a reasonable compromise, and the additional costs are relatively small where there is a miniature $x$-ray service already providing open access for the general practitioners.

\section{R N JoHNSTON}

\section{Chest Clinic, $1 \mathrm{BB}$}

1 Johnston RN, Smith DH. Lancet 1968; ii :588-91.
2 Johnston RN, Smith DH. Lancet 1971;ii:1152-3.

\section{Pain on ejaculation after vasectomy}

SIR,-In "Any questions ?" (6 February, p 408) you report a case of a man with a twoyear history of severe pain on ejaculation starting two years after vasectomy; and Dr G Barry Carruthers suggests a diagnosis of prostatitis, probably unrelated to vasectomy.

Pain with ejaculation following vasectomy is fortunately very rare, but several cases have been documented. ${ }^{12}$ Cures have been reported after excision of a spermatic granuloma-if one can be found ${ }^{1}$; or by vasovasostomy for the relief of congestive epididymitis."

We wish to report that in seven men patients with this distressing symptom, immediate relief has followed a simple manoeuvre which can be carried out under local anaesthetic: this is to open the closed lower end of the vas on the affected side. Spermatozoa are from then on released into and reabsorbed from the scrotal cavity without producing any symptoms or signs of their presence there. In none of our cases has this manoeuvre failed to produce relief; nor has pain recurred over a period of one to three years. Fertility does not return as the upper closed end of the vas remains closed.

We suggest that others might offer this simple and harmless procedure to the occasional man unfortunate enough to suffer pain with ejaculation after his vasectomy.

I S EDWARDS

Cronulla,

(G)

B ERREY

Greenslopes,
Queensland 4120

${ }^{1}$ Schmidt SS. Fertil Steril 1979 ;31 178-81.

2 Shapiro EI, Silber SJ. Fertil Steril 1979;32 546-50.

\section{Endogenous opioid poisoning?}

SiR,-We are grateful to Mr Keith Murray for pointing out that fat embolism might have been the underlying pathology in our patient with "endogenous opioid poisoning" (13 March, $p$ 822). We did consider this diagnosis at an early stage but excluded it as the patient showed no characteristic signs such as inappropriate hyperventilation in the presence of hypoxia, petechiae, or a low platelet count. Patients with fat embolism characteristically hyperventilate in response to hypoxia and are hypocapnoeic, a very different picture from that shown by our case. In fact although the $\mathrm{PaO}_{2}$ fell to $7.9 \mathrm{kPa}(59 \mathrm{~mm} \mathrm{Hg})$ while breathing room air, it rose to $12.3 \mathrm{kPa}(92$ $\mathrm{mm} \mathrm{Hg}$ ) when her inspired oxygen concentration was increased to $35 \%$, even when her respiratory frequency was only four breaths a minute. This picture is characteristic of central respiratory depression, with normal lungs and minimal intrapulmonary shunting.

The striking features of this case were the dramatic response of conscious level and respiratory rate (increasing from four to 20 breaths a minute) to intravenous naloxone and the abnormally high level of cerebrospinal fluid enkephalin.

I E Symons

J V FARMAN

Department of Anaesthesia Addenbrooke's Hospital, Cambridge CB2 2QQ

\section{Preparing a leaflet for patient education}

SIR,-I was interested to read Dr J A Muir Gray's article (17 April, p 1171) as I have recently prepared a leaflet for patients undergoing transurethral resection of the prostate in Oxford.

Dr Muir Gray states that leaflets have been widely and rightly criticised, a bad basis for an article in their defence. I would go so far as to say that leaflets have been widely and rightly praised $^{1-3}$ and having just run a pilot study to evaluate our leaflet can state that $82 \%$ of patients said that they would have liked to have read the leaflet before their operation. I would like to elaborate on the value of running a pilot study, for it is only by doing this that we can find out what the patient wants to know rather than what the doctor thinks the patient wants to know.

As far as transurethral resection of the prostate is concerned $83^{\circ} \circ$ wanted to know how long they would be in hospital; $78^{\circ}$ wanted to know what the operation involved ; and $79 \%$ of those under the age of 70 wanted to read of the effect of the operation on their sex life. Contrast this with the indifference the patients had to how the anaesthetic was given: $55 \%$ thought it was not important to be told (the possibility of a general or a spinal anaesthetic was mentioned in the leaflet), which is a surprising result.

Only by asking patients can we find out what they feel is important, and the medical profession can learn as much from pilot studies such as this as patients can learn about their operation.

TIM BUNKER

Westbury On Trym, 'Nuffield Working Party on Communication with
Patients. Talking with patients. London: Nuffield
Provincial Hospitals Trust, 1980.
' Dunkelman H. Br Med $\mathcal{F} 1979 ; 11: 311-3$.

${ }^{2}$ Dunkelman H. Br Med f 1979;11:311-3.
${ }^{3}$ Hawkins C. Br Med f 1979;ii:638-40.

\section{Cyclophosphamide treatment of} systemic lupus erythematosus: risk of bladder cancer exceeds benefit

SIR,-Dr R W Elliott and colleagues (17 April, p 1160) report the development of invasive bladder carcinoma after prolonged cyclophosphamide treatment in two patients treated for non-malignant disease. They recommend caution in the use of cyclophosphamide in such conditions and also in malignant disease in 